\title{
Phenomenological meaning of foolishness for Christ (Russian version yurodstvo)
}

\author{
Alexey N. Ilyin - Yulya G. Matushanskaya - Rosalina V. Shagieva \\ - Nikolay N. Kosarenko
}

DOI: 10.18355/XL.2020.13.03.06

\begin{abstract}
The relevance of the problem under study is due to contradictions between the ontological prerequisites of "yurodstvo" (foolishness for Christ) as a phenomenon of cultural and social life, phenomenological perceptions of juridical life, as well as views on it from the position of philosophy of religion at the beginning of the XXI century, enrichment of knowledge about its elements and characteristics, which make up the phenomenological meaning of foolishness for Christ. The purpose of the article is to reveal the phenomenological meaning of juridical life, to define it as a phenomenon of cultural, religious and social life, and to identify its ontological grounds. The leading method of studying this problem is the method of comparativetypological analysis, the systemic approach, the sociocultural approach, the principle of historism, the axiological method. At the same time, popular scholarly methods of knowledge were used: analysis and synthesis, climbing from abstract to concrete, ideas of determinism and synergistic historism were used. The article reveals the content of the concept of foolishness for Christ taking into account the ontological component; The elements that serve as phenomenological bases for the maintenance of the foolishness are identified; A methodological analysis of the content of the phenomenological meaning of foolishness for Christ has been carried out, a system of philosophical evaluation of foolishness for Christ has been formulated, and the nature of the presence of juridical life in social life has been analyzed.
\end{abstract}

Key words: Foolishness for Christ, foolishness, divine madness, phenomenological meaning, sanctity, nonlinear rationality of man

\section{Introduction}

The problem of "yurodstvo" (foolishness for Christ) is of high importance in modern philosophy and religious studies. Today, the world faces a large number of unresolved problems that are directly related to various crises - economic, environmental, demographic, political, ethnic, and so on. However, the most important crisis today can be called the spiritual crisis, which hinders the manifestation of human freedom of thought and individuality in all areas of social life. People have found themselves completely defenseless when facing the manifestations of reality that are closely related to the global problems of the modern world, containing a number of ontological contradictions and phenomenological factors that considerably affect the definition of individual freedom, existential choice and responsibility to people. The modern world has immersed in a situation of uncertainty and nonlinear rationality. It is this immersion that causes the effect generating clashes, disasters, disagreements of various scales, and conflicts of various interests, including armed conflicts. The harmonization and humanization of human existence have always been in a particular focus in world history (Rusnakova et al., 2017). The interdependence of man's personal freedom, his choice and specific behavior within the established norms has always been the control tool for social relations that prevented arbitrariness, helped avoid disagreements and served as a factor of sustainable development of society. But sometimes there were unique manifestations of freethinking and individuality in the history of mankind that went far beyond the historically determined social norms. 
Paradoxically, it was these manifestations that contributed to the very harmonization and humanization of the human spirit, due to which people's choice was getting more authentic, conscious, logical and adequate.

In this aspect, special scholarly interest is evoked in connection with the research related to the study of the phenomenological and ontological foundations of such an ambiguous phenomenon as foolishness for Christ. Emblematic non-linearity and irrationality in the sense of uncertainty of the behavior of the holy fool turn out to be special ontological characteristics of the social world, which is based on the instability and fragility of human relationships. The determination of a new quality emerging at this point is a fundamental condition for the existence of humanity.

The whole set of the ideas of determinism (classical (Laplacian), modern (stochastic)) and synergetic historism provides a possibility to take a new look at the processes of genesis, development, and functioning of the world around us and man in it. This is particularly relevant when discussing ambiguous and ontologically undefined processes that undoubtedly include the phenomenon of foolishness. The use of this integrated method helps us see the dialectic of human existence as a variety of mutually determined universal connections, becoming more complex as their number grows. All this occurs in a consistent evolutionary unity of the co-development of nature and human society (the universe and man are here co-evolutionary components). In the course of this process, the worldview of a person and the modern picture of the world undergo a qualitative change. The new worldview is formed in a special indefinite way, emerging as a system that simultaneously obeys the laws of universal evolution and confirms the dynamics of social self-organization. In our research, we proceed from the synergetic paradigm of the development of freedom of thought, individuality and creative individuality of a man. The methodological foundations of classical determinism and synergetic historicism are used. Speaking about the laws of the nature development as a path from chaos to order and vice versa, we can extend the effect of these laws on the development of the social environment, as well as on the processes of the holy fool's personality self-improvement. Indeed, this can be most clearly illustrated by the example of people demonstrating extraordinary, uncertain, original and unpredictable behavior. The idea of classical (Laplacian) determinism presumes complete causality of all processes (both in the nature and in the social sphere.

Purely theological and classical religious (Christian) concept of the emergence and manifestations of foolishness for Christ in the church history, namely, evidence of the exploit of holy foolishness for the sake of Christ is provided in the Lives of the Saints of the Christian Church (Chetyi-Minei) (Rostovsky, 2016).

It is also interesting that the phenomenon of foolishness for Christ was addressed in Russian religious-philosophical, critical and scholar literature. It occurred as late as in the middle of the XIX century. The first source of this kind (extremely critical) can be called the book written in 1864 by N. Barkov (1864) Twenty-Six Moscow False Prophets, False Holy Fools, Male and Female Fools (Barkov, 1864). The most important and detailed studies of Russian authors in this field have appeared since the end of the XIX century. Among them, we can mention the works of priest John Kovalevsky (2000) Folly in Christ and Fools for Christ's Sake of the Eastern and Russian Church, 1895, in a modern re-edition - The Feat of Foolishness and hieromonk A. Kuznetsov (2000) Foolishness and Stolpnichestvo (Stylitism). Religious-and-Psychological, Moral and Social Research, 1912, reprinted in 2000. Here we can also mention the historical and socio-cultural studies of D.S. Likhachev (1984) Laughter in Ancient Russia, 1976, and S.A. Ivanov (1994) Byzantine Holy Foolery, (supplemented and reprinted in 2005, Blissful Pokhaby. The Cultural History of Foolishness (Ivanov, 2005).

In the middle of the XX century, G.P. Fedotov (2004) wrote a historical and philosophical research The Russian Religious Mind, which was published in 2004. A 
special chapter was dedicated to fools. Russian philologists have also made a contribution to the study of foolishness in the global literary thought (Moteyunaite, 2006). Particularly noteworthy is the first attempt to analyze the phenomenon of holy foolishness from the philosophical (or rather philosophical-anthropological) point of view represented in the work of N.N. Rostova (2010), published in 2010. A.N. Ilyin (2013) published a monograph on the ontology of foolishness in 2013.

N.M. Karamzin (2018) studied some issues related to the history of holy foolishness. He focused more on the blessed persons rather than true holy fools (Nicholas Salos of Pskov and Basil the Blessed), while A.I. Goncharov (2004) studied holy fools from historical sources. T.V. Leontyeva (2003) discussed the peculiarities of intellectual abilities in the context of the Russian language using holy fools as an example.

Foolishness for Christ can be recognized as a phenomenon that is very difficult to study using rational approaches. Analyzing the ontological meaning of foolishness, A.N. Ilyin (2008) identified and categorized the main characteristics of foolishness for Christ. He also identified its defining features and revealed the specifics of its complex conditionality. The main trends in the development of ontological understanding of the phenomenon of foolishness in the world philosophical thought were identified in the research of E. Poulakou-Rebelakou, A. Liarmakopulos and C. Tsiamis (2014). The research of J. Bishop and K. Perszsyk (2017) on methodological grounds for determination of the creative abilities of a holy fool by the immediate environment in specific place and time contributed in solving the problem of studying the phenomenon of foolishness for Christ. The works of A. Evangelou (2017a, 2017b) discuss in detail the methodological foundations of traditional and non-traditional teachings about madness, freedom, freethinking and human individuality on the example of the phenomenon of foolishness.

The meaning of nonlinear rationality in the existential manifestation of the phenomenon of foolishness is outlined in the research of T. Bertolotti (2015). W. Desmond (2016) found that changes in the natural environment do not represent a manifestation of transformative freedom in the behavior of the holy fool for Christ but is rather a kind of objective basis for his uncertainty, leading to self-transcendence.

The work of N. Trakakis (2017) provided a possibility to study the imaginary madness and freedom of the holy fool as a specific state of his choice, which is expressed in uncertain actions of ambiguous behavior. In the work of D. Wenkel (2017), the nonlinear rationality of the fool for Christ comprises a special content. The work of P. Laude (2005) is devoted to the study of the image of the holy fool using determinative approaches concerning the divine madness, laughter and its spiritual comprehension.

The theoretical and practical relevance of our work consists in the fact that we use interdisciplinary methods to study the phenomenon of foolishness for Christ, thereby creating a methodology of modern philosophy, in which the boundaries between rational and theological methods can be significantly revised. A holy fool's being is a difficult phenomenon to study. To understand it, we need to set the limits of a new nonlinear rationality. The paradox of studying the phenomenon of foolishness for Christ is that the very methodology of study is similar to the existential manifestations of the holy fool's life. The possibilities of studying the spiritual world must be synchronized with a parallel insight into the existence of the holy fool, paradoxical in its uncertainty.

Our research involved analysis of the phenomenological nature of foolishness for Christ. The data obtained in the course of our research can be quite successfully used to develop a new methodology of natural sciences, as well as in the philosophy of science. The research is of particular value for creating models of social and political processes and technologies. The information contained in this paper can be used for

XLinguae, Volume 13 Issue 3, June 2020, ISSN 1337-8384, ISSN 2453-711X 
individual scholarly research and chapters of academic disciplines in the field of philosophical anthropology and synergistic philosophy, epistemology and synergetic historicism. The results obtained can be applied in the subsequent elaboration of the problem of determining man's creative abilities, which ontologically determines the type of behavior of the individual and stimulates his effectiveness at a particular time and place.

The results of our work can be used in the courses of philosophy disciplines, such as ontology, theory of knowledge, axiology, and sociology. The results of the research will undoubtedly be applicable in further development of such sections as "Phenomenology of Spirituality", "Freedom and Self-Organization of Modern Man", "Ontological Models of Being as Existence", and "Dialectics of Being and Universal Laws of Development". It is expected that the results of the research will be used as a methodological and theoretical basis for the development of disciplines in the field of both natural science and humanities and social studies in the system of basic and further education, as well as in the development of organizational practices related to the training and retraining of managers, teachers and postgraduates, and social workers.

\section{Methodological Bases and Approaches}

The theoretical basis of the work is the ideas of determinism (classical (Laplacian), modern (stochastic)) and synergetic historicism that provide insight into the ontological nature and social conditionality of the phenomenon of foolishness.

The methodological foundation of the research is the principles of determinism and synergetic historicism that determine the phenomenological dependence of foolishness for Christ on natural, social and spiritual reality. Foolishness for Christ is conditional upon the determination of spiritual characteristics of the individual that materialize in the context of specific place and time. The principle of determinism as it is applicable to the study of the phenomenality of the fool for Christ is the most important in determining the causality of the phenomenal manifestations of his life.

Other criteria of determinism are also used in the study, namely, the rationality of knowledge of the social life phenomena, availability of empirical experience and stating generalization of historical facts for analysis, inclusion of accumulated knowledge in the system, and reliance on established philosophical traditions.

In our work, we used the methodology of synergetic historicism. Within the framework of this concept, the ideas of classical determinism are subjected to constructive criticism, where the linear definition of human freedom faces problems arising in so far as exposed to the effects of uncertainty. In the context of synergetic historicism, freethinking and individuality of the holy fool are viewed as a fundamental objective condition and aspect of self-organization of individual and social reality in particular place and time. Hence, the ontological foundations of the holy fool's characteristics can be identified, first of all, his freedom of thought and individuality in the general mechanisms of self-organization of his existence. The freedom of the holy fool is the key and integral element, which enables qualitative spiritual transformations in social reality due to the uniqueness and unpredictability of the holy fool's behavior.

The principles of objectivity, dialectics, system analysis, and knowledge formalization were used in this work, as well.

In our study, we attempted a philosophical (phenomenological) analysis of the phenomenon of foolishness for Christ.

It was revealed that the foolishness for Christ is strictly determined by the natural, social and spiritual realities of human life and activity, and the triune nature of the determination of foolishness for Christ was substantiated. We have found that nature, social life, and the spiritual life of man strictly determine the foolishness for Christ in different proportions in the context of specific place and time. The conclusion was 
made that the spiritual sphere is the main determinant of foolishness as the highest degree of its ideological manifestation and spiritual significance.

The dialectic of objective conditions for the formation of the phenomenon of foolishness for Christ was discussed with a glance to specific social and historical conditions. In our research, it was identified that the problem of the emergence of foolishness in the historical development of mankind is determined by historical realities and can be designated as an evolutionary trinity:

- anthropogenesis, that is, the origin of man from an ape-like creature;

- sociogenesis, that is, the formation and development of human society;

- cultural genesis, that is, the birth of culture.

Each of these components has its own specifics. Anthropogenesis materializes at the border of biological and social forms of movement of living things. Sociogenesis materializes right within the very boundaries of the social form of movement of living things.

The natural component of foolishness for Christ determines the importance of natural factors for the formation of the holy fool's personality.

The social component of the holy fool's personality reveals the role of social relations in the formation of the holy fool's personality. The scholarly definition of the phenomenon of foolishness stems from the understanding of its social and specific historical nature. For the holy fool, society as the fundamental basis of human life is both an external and internal condition for a pronounced existence, special existential manifestations of his life and activity.

The cultural (spiritual) component of the phenomenon of foolishness for Christ is decisive in the holy fool's behavior and is part of the practice of his life, characterized in a special way by manifestations of moral influence on various social communities. The holy fool's behavior within the framework of spiritual transformation is conditioned by various needs of his ascetic life. We believe that the pivotal programme of the holy fool's behavior is manifested not through natural factors, but rather through spiritual culture, corresponding to the level of social development prevailing in a particular era.

\section{Results}

The philosophical analysis of the phenomenon of foolishness for Christ involved the identification of the phenomenological nature of evidence of the holy fool's life that are most significant in social and religious practice. In order to theoretically substantiate the idea of the uncertain nature of foolishness for Christ, the nature of this phenomenon was specifically studied in the context of particular place and time. These studies have significantly contributed to the identification of the phenomenological bases of foolishness in the context of exposure to the effects of uncertainty in social existence.

The use of integrated research methods enabled us to identify the factors that determined the phenomenological basis of foolishness for Christ. Our study is dedicated to comprehending the phenomenological bases of foolishness, both from the standpoint of classical determinism and in the context of synergetic historicism, with reference to psychological theories of human personality. We discovered the sources of the nonlinear nature of freedom and individuality of the fool for Christ in the general dynamics of self-organization of human existence, and they point at nonlinearity and uncertainty, a special kind of instability, as factors of pivotal fundamental significance in their materialization.

The contradictory existence of the fool for Christ is a manifestation of the unity of the rational, irrational, and extra-rational in their dialectical unity. It is a process in which freedom of choice, deep freethinking, and a holy fool's individuality transcending reason materialize. The existence of the fool for Christ manifests itself through a huge

XLinguae, Volume 13 Issue 3, June 2020, ISSN 1337-8384, ISSN 2453-711X 
variety of potential possibilities for the implementation of ideas: from expressing clear, adequate reasoning, rationally formed ontological structures and creative activity, practical transformative work aimed at the real spiritual transformation of the world to completely unpredictable and ambiguous, to the extent of their uncertainty, elements of an illogical and dangerous action as an element of self-expression.

In the historical context, we have identified the idea that the existence of the holy fool is a contradictory unity of reason and feelings, mind and madness as they are expressed in their unpredictability and uncertainty, yet openness to society. The combination of these characteristics makes the phenomenon of foolishness for Christ look completely realistic.

We have discovered a characteristic which sets the boundaries of the existential grounds of foolishness for Christ. In general, such grounds are necessary and sufficient conditions for the materialization of potential existential characteristics of the fool in specific place and time. The holy fool's existence is marked with a power of transition of being into non-being, a self-organizing factor of unity, formation and self-renewal of sources of self-organization that in general determine the phenomenological nature of the holy fool's existence.

In our research, we have identified a significant functional place of uncertainty and randomness in the materialization of reasonable and insane principles, freedom and individuality in the fool's being. At the same time, an objective chance in the existence of the holy fool necessarily intersects with the subjective nature of the holy fool's implementation of his ideas. This fact determines a high degree of complexity and unpredictability of the holy fool's being, the critical uncertainty of his life and the role of chance in the future. All this inevitably leads to the emergence and increase of various types of uncertainties that cause increased responsibility for the holy fool's actions.

In our research, we have obtained solid evidence of the thesis that the nonlinear rationality of the holy fool, his freedom, individual traits, creativity and ambiguity of behavior determine the special presence of foolishness in the existence of the world, emphasizing the effect of nonlinear rationality, which is a fundamental phenomenological power in the process of the world's self-development. A detailed insight into the dialectic of mind, reason, and madness in the context of the behavior of the holy fool allowed us to identify the ambiguous meaning of the holy fool's phenomenological manifestations. We have found that the boundaries of the holy fool's mind and madness are very conditional and tend to change. The reason is limited by the nature of madness in relation to the ambiguous and uncertain situations of social life. The characteristic that defines the phenomenological meaning of foolishness for Christ is the nonlinear rationality of the holy fool.

We also attempted to identify the special creative role of nonlinear rationality in the implementation of the fool's vital forces in the context of the social conditions of his existence. The fools's actions generate specific effects of nonlinear rationality that are an expression of uncertainty and unpredictability of his behavior. These effects are the tools for comprehending the instability of being. The holy fool's life activity is a manifestation of the sense-generating actions of the self-organizing world.

In addition, our research analyses the determinative nature of natural and social evolution. The co-development of nature and society is the fundamental basis for the world's existence. Fools bring an element of harmonization of nature and society by means of their ambiguous life activities.

The study of the Orthodox concept leads us to the conclusion that prophets, madmen, and fools serve as tools of the spiritual world, which is incomparably more extensive and multidimensional than our own - a world that goes beyond the limits of specific, narrow "human" specialization. 
The fool for Christ gradually attains a special level of vision of the existential boundaries of his own existence. He expresses the understanding of creative thought as a possibility of self-transcendence, conditioned by the holy fool's self.

The mentioned reasons and factors that determine the phenomenological nature of foolishness for Christ, the personal traits of the holy fool, and the criteria for identifying the phenomenon of foolishness together make up a system which denotes the nature of the presence of foolishness in social life from the standpoint of determinism and is focused on identifying the phenomenon of foolishness for Christ in the religious sphere and public life (Figure 1).

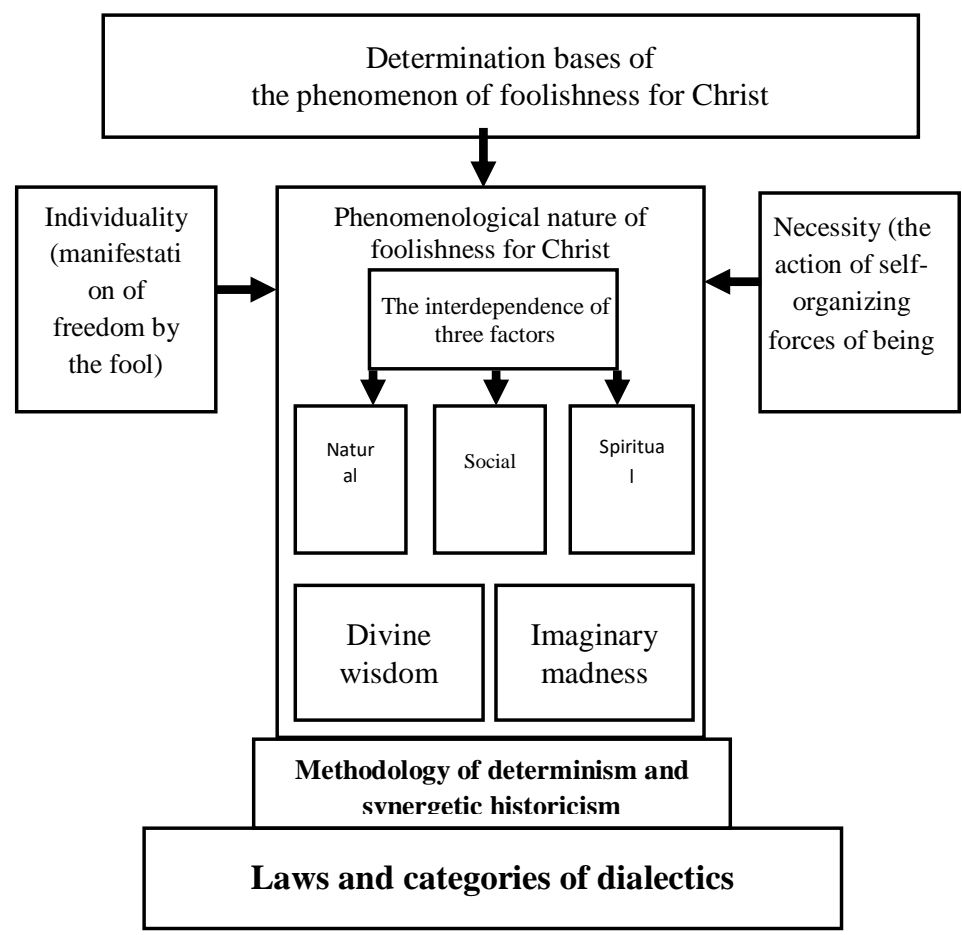

Figure 1. System of philosophical evaluation of foolishness for Christ

\section{Discussion}

At the beginning of the XXI century, the phenomenon of foolishness for Christ was studied using approaches of various disciplines that have a philosophical, biological (physiological and ethological), psychological, religious, and social nature. The problem of foolishness for Christ were discussed by representatives of various fields of knowledge, such as physiology, psychology, cultural studies, sociology, and by Christian theologians. Hermeneutical concept of the phenomenon of foolishness for Christ is provided in the study of M. Grau (2014). The information regarding the fact that an active process of attaining the level of semi-transparency by the holy fool occurs in the context of overcoming social boundaries of the world's certainty, through special characteristics of the holy fool that are the result of freedom, individual uniqueness of existential manifestations, freedom of choice and responsibility to the society, is identified in the work of S. Fuller and V. Lipinska (2014). This idea is further elaborated in the works, providing insights into the effect 
of determinative bases on human freedom and the formation of mass national consciousness. The processes that influence changes in mass consciousness are significant prerequisites for the emergence of specific features of the mentality of large ethnic groups and even peoples. Research in this area is very relevant today. In the general cultural context, this problem is discussed by Russian researchers. Another study shows that holy foolishness is based on the talent for spiritual leadership. The research of P. Vaskovic (2019) defines the extent, to which the phenomenological method is applicable to studying difficult social phenomena, which definitely include the phenomenon of foolishness for Christ. P. Bloomfield (2017) studied the issues of morality and the complexity in determining the effect of moral norms and identified their presence in social life. Focusing on the complex interweaving of reason and madness in situations of existential choice, K. Froese (2017) showed in his work that when determining the applicability of the mind, philosophers often go beyond the boundaries of madness and laughter. Developing this idea, L. Moland (2018) demonstrates that in classical philosophizing there is a place for ironic phenomenological research. We made an attempt to go beyond the usual rationality. In this context, interest is raised by the research conducted by K. Lieberman (2017). This paper provides examples of expanding the boundaries of the phenomenological method, which affected the possibility of studying the foolishness for Christ. C. Meister (2014) showed that the religious ascetic life is marked with miracles produced by holy ascetics, among which the fools for Christ hold a prominent position. The study of these miracles is associated with difficulties in crossing the boundaries of a mystery that cannot be studied by rational methods. The research by $\mathrm{C}$. Pamment (2017) provides a strong argument in favor of the fact that the world of religious miracles can be traced both in Christianity and in Islam, particularly, in Sufi practice. Exploring the religious practice of Judaism, Tandlich elaborates this idea. All of the above works are dedicated to particular aspects of foolishness for Christ. Further research of the phenomenon of foolishness is associated with the difficulties of studying the spiritual world of the individual using rational approaches. The phenomenological nature of foolishness requires comprehensive research in the context of ontological justification of the holy fool's nonlinear and indefinite consciousness. A number of questions remain open that are aimed at studying the presupposition of the phenomenon of foolishness, including the question of identifying the causality of the emergence of foolishness for Christ, and the study of the ontological foundations of this phenomenon.

Within the framework of modern ontological and phenomenological research of social life, the established grounds for the rational study of reality undergo re-evaluation. There is a serious problem in the study of the phenomenon of foolishness for Christ that concerns the crisis of man's identity caused by the effect of self-organizing forces. The definition of the nature of objectively acting forces in the holy fool's existence indicates the complex nature of the applicability of his vital energy in social life. The fundamental characteristic of the holy fool is his desire to expand the meaning of the existential manifestations of human freedom and individuality. In this context, the fool acts and develops in accordance with the self-organizing forces of the universe and thus sets the direction of his dialectical development and self-improvement.

\section{Conclusion}

As a result of our research, the fundamental phenomenological bases of foolishness were analyzed, and the content of the concept of foolishness for Christ was revealed, taking into account the ontological component. The phenomenological bases of foolishness are freedom, individuality, and a complex, non-linear relationship between reason and imaginary madness. Foolishness is a unique manifestation of freedom and necessity in the activity of the subject, where freedom and responsibility are intertwined in a completely unpredictable way. Foolishness for Christ is a unique 
phenomenon of social life and is closely intertwined with the context of selforganization of nature and society. The imaginary madness of the fool is associated with his boundless freedom, individual uniqueness, freethinking and active position in relation to the phenomena of social life. This fact is obviously a necessity from the standpoint of evolution. The holy fool's existence is abundant in special intentions of self-development and connects imaginary madness and Divine reason, clarity and uncertainty, ontology and phenomenology. The characteristics of holy fool's existence that can be expressed qualitatively and quantitatively can serve as evidence of an ever-increasing evolutionary necessity, in which the ambiguity and uncertainty of existential manifestations are more like special factors of the holy fool's individual development. Modern philosophers and theologians recognize that the phenomenon of foolishness for Christ cannot be univocally determined and causally expressed. The combination of the methodology of classical determinism and synergetic historicism allows us to approach the internal nature of such an undefined phenomenon in a different way. The new determination shows the activity of self-organizing forces in the context of the pronounced uncertainty and unpredictability of the holy fool's existence and ambiguously interpreted situations of his life. The peculiarities of foolishness for Christ are manifested through Divine wisdom and imaginary madness. An attempt is made to reveal the nature of the phenomenon of foolishness for Christ. It is found that the phenomenological nature of foolishness for Christ is determined by the interdependence of three factors, namely: natural, social and spiritual factors.

Methodological analysis of the phenomenological meaning of foolishness for Christ revealed a number of essential characteristics of foolishness, such as

- the nonlinear nature of the phenomenon of foolishness for Christ, which can only be explained from the perspective of integrated approaches of determinism (classical (Laplacian), modern (stochastic)) and synergetic historicism;

- the life activity of the holy fool is an expression of the complex dialectic of reason and madness;

- freedom and individuality in the context of the clearly expressed social role of the holy fool act as a determinant of the holy fool's transition to the level of selftranscendence.

The system of philosophical evaluation of foolishness for Christ comprises the laws and categories of dialectics, the methodology of determinism, the determining grounds for the manifestation of foolishness for Christ, individuality and necessity as necessary elements of the phenomenon of holy foolishness.

The materials of the article can be useful for teachers and professionals in the field of science and culture who are interested in the development of culture, philosophy and religion.

In the course of the research, a number of questions arose, which determines the need to continue the research and search for new approaches and methods in studying the problems of presupposition of the phenomenology of holy foolishness as one of the manifestations of nonlinear rationality.

\section{Bibliographic references}

BARKOV, N. 1864. Twenty-six Moscow, Other-Prophets, Other-Jurodyh, Fool and Fool. Moscow: Typography I Semyona. ISBN is not present.

BERTOLOTTI, T. 2015. Digitalizing the Religious Niche (and Vice Versa). In: Patterns of Rationality. In: Studies in Applied Philosophy, Epistemology and Rational Ethics, vol 19, pp. 215-257. ISBN 978-3-319-17785-4 (Print) 978-3-319-17786-1 (Online).

BISHOP, J. - PERSZSYK, K. 2017. The Divine Attributes and Non-Personal Conceptions of God. In: Essays on the Metaphysics of the Divine, vol. 36, n. 4, pp. 609-621. ISSN 0167-7411 (Print) 1572-8749 (Online). 
BLOOMFIELD, P. 2017. Morality is Necessary for Happiness. In: Philosophical Studies, vol. 174, n. 10, pp. 2613-2628. ISSN 0031-8116 (Print) 1573-0883 (Online). DESMOND, W. 2016. Idiot Wisdom and the Intimate Universal: On Immanence and Transcendence in an Intercultural Perspective. In: Brown N., Franke W. (eds) Transcendence, Immanence, and Intercultural Philosophy. Cham: Palgrave Macmillan. ISBN 978-3-319-43091-1(Print) 978-3-319-43092-8 (Online).

EVANGELOU, A. 2017a. History of Madness: Is There Such a Thing as Madness? In: Philosophizing Madness from Nietzsche to Derrida. Cham: Palgrave Macmillan. ISBN 978-3-319-57092-1 (Print) 978-3-319-57093-8 (Online).

EVANGELOU, A. 2017b. Nietzsche and Madness. In: Philosophizing Madness from Nietzsche to Derrida. Cham: Palgrave Macmillan, pp. 153-171. ISBN 978-3-31957092-1 (Print) 978-3-319-57093-8 (Online).

FEDOTOV, G. 2004. Collection of Works in 12 T.T. TXI: Russian Religious. Part 2. Middle Ages. XIII-XV centuries. Moscow: Martis. ISBN 5-7248-0077-7.

FROESE, K. 2017. We Have a Body! Kant, Schopenhauer and Bergson. Cham: Palgrave Macmillan. ISBN 978-3-319-55043-5 (Print) 978-3-319-55044-2 (Online).

FULLER, S. - LIPINSKA, V. 2014. Proactionary Theology: Discovering the Art of God-Playing. In: The Proactionary Imperative. London: Palgrave Macmillan. ISBN 978-1-137-43309-1 (Print) 978-1-137-30292-2 (Online).

GONCHAROV, A. 2004. Entelechia jurodstvo in the Word of Mikhail Zaytnik. In: Journal of the Voronezh State University, n.1, pp.92-102. ISSN 1814-2958.

GRAU, M. 2014. Fool's Errand: Holy Fools and Divine Folly as Hermeneutical Figures. In: Refiguring Theological Hermeneutics. New York: Palgrave Macmillan. ISBN 978-1-349-46000-7 (Print) 978-1-137-32455-9 (Online).

ILYIN, A. 2008. Problem of measurement of leader endowments. In: Bulletin of the Bashkir university, vol. 13, n. 4, pp. 1055-1057. ISSN 1998-4812.

ILYIN, A. 2013. Ontological meaning of urodship: Monography. Edited by Professor O.I. Kirikov. Moscow: Science: Inform; Voronezh: VGPU. ISBN 978-5-00044-023-2 IVANOV, S. 1994. Byzantine juridical. Moscow: Mezhunar. Relations. ISBN 5-71330761-1.

IVANOV, S. 2005. Blessed lust: Cultural history of juridical origin/S.A. Ivanov; Grew. academy of Sciences. In-t Slavic studies. Moscow: Languages of Slavic cultures. ISBN 5-9551-0105-5.

KARAMZIN, N.M. 2018. History of the State of Russia. Moscow: Alfa-Kniga. ISBN 978-5-9922-0089-8.

KOVALEVSKY, I. 2000. The Feat of Jurodstvo. Moscow: Lepta-Press. ISBN 594000-011-8.

KUZNETSOV, A. 2000. Juridical and pillar-making. Religious-Psychological, Moral and Social Research. Moscow: Publishing House of Holy Trinity Sergei Lavra. ISBN 5-7789-0100-3.

LAUDE, P. 2005. Fools for Christ's Sake. In: Divine Play, Sacred Laughter, and Spiritual Understanding. New York: Palgrave Macmillan. ISBN 978-1-349-53173-8 (Print) 978-1-4039-8058-8 (Online).

LEONTYEVA, T.V. 2003. Intelligence of man in the mirror of the Russian language: $\mathrm{PhD}$ Thesis. Yekaterinburg, $24 \mathrm{p}$. ISBN is not present.

LIEBERMAN, K. 2017. What Can the Human Sciences Contribute to Phenomenology? In: Hum Studies. vol. 40, n. 1, pp. 7-24. ISSN: 0163-8548 (Print) 1572-851X (Online).

LIKHACHEV, D.S. 1984. Laughter in Ancient Russia. Leningrad: Science. ISBN is not present.

MEISTER, C. 2014. Religion, Science, and Miracles. In: Philosophy of Religion. Palgrave Philosophy Today. London: Palgrave Macmillan. ISBN 978-0-230-23291-4 (Print) 978-1-137-31475-8 (Online). 
MOLAND, L. 2018. Reconciling Laughter: Hegel on Comedy and Humor. In: Moland L. (eds) All Too Human. Boston Studies in Philosophy, Religion and Public Life. Cham: Springer. ISBN 978-3-319-91330-8 (Print) 978-3-319-91331-5 (Online).

MOTEYUNAITE, I. 2006. Find out I.V. Perception of juridical character by Russian literature of the XIX-XX centuries. Pskov: Without a publisher. ISBN 5-85143-006-0. PAMMENT, C. 2017. Brahmin Jesters and Sufi Wise Fools. In: Comic Performance in Pakistan. Palgrave Studies in Comedy. London: Palgrave Macmillan. ISBN 69-103. 978-1-137-56630-0 (Print) 978-1-137-56631-7 (Online).

POULAKOU-REBELAKOU, E. - LIARMAKOPULOS, A. - TSIAMIS, C. 2014. Holy Fools: A Religious Phenomenon of Extreme Behaviour. In: Relig Health n. 53, pp. 95-104. ISSN 0022-4197 (Print) 1573-6571 (Online).

ROSTOVA, N.N. 2010. The Man of Reverse Perspective (Experience of Philosophical Reflection of the Phenomenon of the Juridical of Christ for the Sake). Moscow: MGIU. ISBN 978-5-2760-1597-2.

ROSTOVSKY, D. 2016. Lives of saints in Russian, presented according to the guidance of Chetny-Miney Saint Dimitriy Rostovsky in 12 tons. Moscow: Voskresenye, Eksmo. ISBN 978-5-6998-7876-5.

RUSNAKOVA, J. - RUSNAK, J. - ROSINSKY, R. - ROCHOVSKA, A. ODRASKOVA, B. (2017). What do pupils' parents think about school segregation? In: PorOwnania, vol. 2, n. 21, pp. 269-284. ISSN 1733-165X.

TRAKAKIS, N. 2017. Philosophy and Religious Commitment. In: Sophia, vol. 56, n. 4, pp. 605-630. ISSN 0038-1527 (Print) 1873-930X (Online).

VASKOVIC, P. 2019. The Path to Authenticity: Kierkegaard and Dostoyevsky on existential transformation. In: International Journal for Philosophy of Religion, n.1, pp. 1-28. ISSN 0020-7047 (Print) 1572-8684 (Online).

WENKEL, D. 2017. The Theology of Beating the Fool. In: Jesus' Crucifixion Beatings and the Book of Proverbs. Cham: Palgrave Macmillan. ISBN 978-3-31948269-9 (Print) 978-3-319-48270-5 (Online).

Words: 6157

Characters: 42001 (23,33 standard pages)

Assoc. Prof. Alexey N. Ilyin

Department of Humanitarian Education and Sociology

Almetyevsk State Oil Institute

2 Lenin Street,

423450 Almetyevsk,

Russian Federation

alexeyilyin.74@mail.ru

Assoc. Prof. Yulya G. Matushanskaya

Department of Religious Studies

Kazan (Volga region) Federal University

35 Kremlin Street

420008 Kazan

Russian Federation

Jgm2007@yandex.ru

Prof. Rosalina V. Shagieva

Department of Private Law

State University of Management

99 Ryazanskiy Prospect

109542, Moscow

XLinguae, Volume 13 Issue 3, June 2020, ISSN 1337-8384, ISSN 2453-711X 
Russian Federation

shagsas@mail.ru

Assoc. Prof. Nikolay N. Kosarenko

Department of State Legal and Criminal Law Disciplines

Plekhanov Russian University of Economics

36 Stremyannyi Pereulok

115093, Moscow

Russian Federation

nkosarenko@yandex.ru 